\title{
One Country, One Vote? Labor Market Structure and Voting Rights in the ECB
}

\author{
Helge Berger \\ Free University of Berlin \\ Carsten Hefeker \\ University of Siegen
}

\begin{abstract}
The pending enlargement of the European Monetary Union (EMU) has brought to the fore the discussion of the voting right distribution in the European Central Bank (ECB) council. We show that, in a model where labor unions internalize the inflationary consequences of wage setting, deviating from a voting scheme based purely on economic size can be beneficial. Preliminary evidence on unemployment and voting rights in the ECB council seems broadly in line with this idea. We also point to possible policy implications for EMU enlargement and ECB restructuring.
\end{abstract}

- JEL Classifications: D72, E58

- Key words: Monetary Policy, Wage Setting, European Monetary Union, European Central Bank, Euro Area, ECB Reform, EMU Enlargement, Accession Countries

\section{Introduction}

Voting in the council of the European Central Bank (ECB) is organized according to the "one country, one vote" principle, with the national central bank

\footnotetext{
*Corresponding address: Helge Berger, Free University of Berlin, Boltzmannstr. 20, 14195 Berlin, Gernany. Tel: +49-30-828-54037, Fax: +49-30-838-56633, E-mail: hberger@wiwiss.fu-berlin.de. Carsten Hefeker, University of Siegen, Holderlinstr. 3, 57068 Siegen, Germany. Tel: +49-271-740-3184, Fax: +49-271-740-4042, E-mail: carsten.hefeker@uni-siegen.de (c)2005-Center for International Economics, Sejong Institution, All Rights Reserved.
} 
governor of, for example, Luxembourg holding similar voting power as the French governor. This is in remarkable contrast to the way the number of commissioners in the European Commission is distributed among EU member countries or the number of representatives in the European Parliament, both of which are a function of relative population sizes. Without a reform of the ECB decision-making process, these differences between political and economic weights will become even more pronounced as most accession countries to the European Monetary Union (EMU) are relatively small in size.

Misrepresentation of economic size could distort the European perspective of the ECB council (Berger 2002)-but should a reform of ECB decision making go as far as to fully abandon the idea of "one country, one vote"? A number of considerations suggest that some asymmetry in the representation of economic size in the ECB council might have its benefits. Casella (1992) argues that smaller countries might require a political premium in terms of a more than proportional weight in common decisions as a precondition to joining a political union. Thus (some) overrepresentation could be an integral part of EMU itself. Another argument in favor of asymmetry in representation might be differences in transmission mechanisms. As pointed out by, among others, De Grauwe (2000), Gros and Hefeker (2002), and Benigno (2003), it might be advisable to take into account differences in the impact of monetary policy on real and nominal variables when weighing economic developments in the euro area. A corollary of this result is that voting rights should under some circumstances differ from economic size. In addition, the "one country, one vote" principle could help foster ECB independence by decentralizing the appointment process to the council (Berger 2002).

The present paper stresses another channel to explain over- and under representation of countries in the ECB's council: the interaction of monetary policy and labor market structure within a currency union. Building on a recent literature exploring the relation between labor unions and central banks in a closed economy, we show that deviating from a voting scheme based purely on economic size can be beneficial if unions internalize the inflationary consequences of wage setting. ${ }^{1}$

To illustrate the underlying idea, consider a monetary union with two member countries of equal size but asymmetric labor market structure - in particular, assume a large number of unions in one country (country 1 ) and very few unions in

${ }^{1}$ See, among others, Cukierman and Lippi (1999, 2001), Grüner and Hefeker (1999), Guzzo and Velasco (1999), Berger et al. (2001). 
the other (country 2). If, for given central bank preferences, the central bank puts greater emphasis on country 1, monetary policy will attempt to increase inflation to foster employment in country 1 . In anticipation, unions can be expected to moderate their wage demands, thereby lowering real wages and unemployment in country 1 . At the same time, the single union in country 2 will be increasing wages - but only moderately so. While it has an incentive to increase wages as the central bank shifts attention to country 1 , the union will be cautioned by fears of higher inflation. As a consequence, inflation in the currency union will be falling; employment in country 1 could be increasing; and employment in country 2 is likely to be decreasing. Depending on the prevailing view of the unemploymentinflation trade-off, however, the overall outcome might improve welfare even in countries where unemployment increases. This would make a voting scheme that deviates from economic size a beneficial policy option for all currency area members.

Interestingly, empirical evidence seems to support the notion that the existing distribution of economic and political weights in the ECB council could be influenced by similar arguments. There are indications of a negative correlation between unemployment and voting power in excess of a country's economic weight.

These results have implications for ECB reform in light of EMU enlargement. While the asymmetries between economic and political weight are bound to increase in a larger monetary union, a too ambitious overhaul of the "one country, one vote" principle might have disadvantages - at least from the perspective of the new (mostly small) member countries. Since many accession countries are characterized by competitive labor markets compared to present EMU members they are bound to benefit from entering EMU with voting rights in excess of their relative size. On the other hand, with inflation already at rather low levels, existing members might find that a further reduction in voting rights is not to their advantage.

We proceed as follows: section 2 develops a simple model describing the interaction between a common central bank and labor unions in a currency union with two member countries. Sections 3 and 4 derive the influence of relative voting weights in monetary policy decisions on inflation and labor market outcomes. Section 5 relates these results to observable labor market characteristics of EMU members and discusses some implications for EMU enlargement and ECB reform. Section 6 draws some conclusions. 


\section{The Basic Model}

\section{A. The Labor Market}

We consider two economies $(j=1,2)$ with $i=1 \ldots n_{j}$ sectors each in a monetary union. Labor is sector and country specific. Total labor demand in country $j$ is

$$
L_{j}^{d}=\sum_{i=1}^{n} \frac{L_{j}}{n_{j}}\left(1-\left(w_{i}-\pi\right)\right)
$$

and unemployment is

$$
u_{j}=\frac{L_{j}-L_{j}^{d}}{L_{j}}=\bar{w}_{j}-\pi
$$

where $L$ is the total labor supply and $\bar{w}_{j}=\frac{1}{n} \sum_{i=1}^{n} w_{i}$ is the average wage demand. The market clearing real wage $\left(w_{i}-\pi\right)$ in sector $i$ is normalized to zero. We assume that the rate of inflation is the same across countries and sectors. The number of labor unions $n_{j}$ in each economy is exogenous and is interpreted as an indicator of the degree of national labor market competitiveness. A highly decentralized, and thus presumably more competitive, labor market is characterized by a higher number of unions (Calmfors and Driffill 1988).

\section{B. The Monetary Authority}

Monetary policy is determined by a central bank council that is composed of a jointly appointed board (e.g., in the case of the ECB: president, vice-president and four other members of the ECB directorate) and representatives for each member country in the monetary union. A common assumption is that the national representatives are driven-to an important degree-by developments in their national economies. $^{2}$

In particular, we assume that national representatives in country $j$ dislike inflation and unemployment, preferring both to be close to zero. If $\lambda>0$ measures their relative preference for low unemployment, the loss function of representative $j$ can be written as

$$
L_{j}=\pi^{2}+\lambda u_{j}^{2}
$$

\footnotetext{
${ }^{2}$ See, among others, von Hagen and Süppel (1994), Grüner (1999), Berger (2002), Hefeker (2003). Meade and Sheets (2002) and Berger and de Haan (2002) present preliminary evidence supporting this view.
} 
Members of the board are assumed to care for currency union wide developments and to show no national preferences-perhaps, as in the case of the ECB, because of a supra-national appointment procedure. The weight that the board assigns to developments in country $1,0<\chi<1$, equals its relative economic size. Country 2 's weight is $1-\chi$. Thus the board's preferences can be described by the loss function

$$
L_{B}=\pi^{2}+\lambda\left[\chi u_{1}+(1-\chi) u_{2}\right]^{2}
$$

where we have made the assumption that inflation is the same across the currency union.

Finally, we describe the preferences of the decision making body, the central bank council, as a weighted combination of the board and the two national representatives:

$$
L_{c}=b L_{B}+(1-b)\left[\gamma L_{1}+(1-\gamma) L_{2}\right]
$$

The relative political weight of the board is $b$ and the relative weight of each national representative is $\gamma$, with $0<b, \gamma<1$. Based on the "one country, one vote" principle, $\gamma$ would be $1 / 2$. Note that we impose similar preferences on all the monetary policy makers. ${ }^{3}$

Given this preference structure, the rate of inflation that is chosen by the council is

$$
\pi=\theta\left(s_{1} \bar{w}_{1}+s_{2} \bar{w}_{2}\right)
$$

where $\theta=\lambda /(1+\lambda), s_{1}=b \chi+(1-b) \gamma$ and $s_{2}=b(1-\chi)+(1-b)(1-\gamma)$. Note that the composite weights $s_{j}$ are a function of both the influence of the countries relative to their peers in the ECB council $\gamma_{j}$ and the economic weight that the board assigns to this country $\chi_{j}$. The parameter $\theta<1$ measures the central bank's reaction to wages in the two economies.

\section{The Labor Unions}

In what follows we assume that preferences of all national labor union members are identical. The objectives of the representative member include high real wages,

\footnotetext{
${ }^{3}$ We are only interested in the systematic influence of a country's political weight in monetary policy decisions.
} 
low inflation, and low unemployment (see Cukierman and Lippi 1999, 2001, Grüner and Hefeker 1999). With preference parameters $c>0$ and $a>0$ we can write:

$$
U_{i j}=\left(w_{i j}-\pi\right)-\frac{c}{2} \pi^{2}-\frac{a}{2} u_{i j}^{2}
$$

Unions are willing to trade in full unemployment for higher real wages. The term $1 / a$ is a measure of union aggressiveness in this regard. It is determined by the influence of (employed) labor union insiders relative to outsiders; and it also reflects national labor legislation because this determines labor turnover costs and rigidities and thus the insiders' power in wage setting (Lindbeck and Snower 1988). In addition, union members are inflation averse, reflecting, for instance, negative effects of inflation on the real value of social benefits, pensions, or nominal assets of union members (Cubitt 1992, Scott 1997).

By construction, the labor union in sector $i$ is Stackelberg leader vis-à-vis the central bank. That is, labor unions take the rate of inflation and how their wage setting influences inflation into account when determining their wage demands. In a fully symmetric equilibrium (where $w_{i j}=\bar{w}_{j}$ ), the wage reaction function of unions in country 1 is $^{4}$

$$
w_{1}=\frac{n_{1}-\theta s_{1}+w_{2} \theta s_{2}\left[a\left(n_{1}-\theta s_{1}\right)-c \theta s_{1}\right]}{a\left(n_{1}-\theta s_{1}\right)\left(n_{1}-\theta s_{1}\right)+c\left(\theta s_{1}\right)^{2}} .
$$

The reaction function illustrates that wages in both member countries are strategic complements only to a point: when inflation aversion is large enough, unions fear that wage demands from the other country will prompt the central bank into an inflationary response that should be avoided (or limited) by lowering their own wage demands. Thus, inflation aversion works as a disciplining force on labor unions.

Based on (6) we can calculate the equilibrium nominal wage demand in country 1:

$$
w_{1}=\frac{a\left(n_{1}-\theta s_{1}\right)\left(n_{2}-\theta s_{2}\right)+c \theta^{2} s_{2}\left(n_{1} s_{2}-n_{2} s_{1}\right)}{a\left[a(1-\theta)\left(n_{1}-\theta s_{1}\right)\left(n_{2}-\theta s_{2}\right)+c \theta^{2}\left[\left(n_{1}-\theta s_{1}\right) s_{1}^{2}\right]\right]}
$$

Equilibrium wages in country 1 are determined by the labor market structure in

${ }^{4}$ The focus is on country 1 . Results for country 2 are similar and can be obtained by substituting indices. 
both economies (measured by $n_{j}$ ), the degree of inflation aversion of unions in both countries $(c)$, the central bank characteristics determining inflation $(\theta)$, and the distribution of political power in the monetary policy decision-making process $\left(s_{j}\right)$. For values of $s_{1}$ close to 1 , nominal wage demands can be shown to be decreasing in $c$ and be increasing in the number of national labor unions (for $c>0$ ).

\section{Inflation and Real Wages in Member Countries}

Combining nominal wage demands in the two countries, the rate of inflation can be calculated from (4) as:

$$
\pi=\theta \frac{a\left(n_{1}-\theta s_{1}\right)\left(n_{2}-\theta s_{2}\right)+c \theta^{2} s_{2}\left(n_{1} s_{2}-n_{2} s_{1}\right)}{a a(1-\theta)\left(n_{1}-\theta s_{1}\right)\left(n_{2}-\theta s_{2}\right)+c \theta^{2}\left[\left(n_{1}-\theta s_{1}\right) s_{2}^{2}+\left(n_{2}+\theta s_{2}\right) s_{1}^{2}\right]}
$$

Not surprisingly, equation (8) mirrors equilibrium nominal wages. The influence of the unions' inflation aversion hinges on the relative weights of the two countries and their respective labor market structures. This is also true for real wages, defined as $\hat{w}_{j}=w_{j}-\pi:$ :

$$
\hat{w}_{1}=\frac{a(1-\theta)\left(n_{1}-\theta s_{1}\right)\left(n_{2}-\theta s_{2}\right)+c \theta^{2} s_{2}\left(n_{1} s_{2}-n_{2} s_{1}\right)}{a\left[a(1-\theta)\left(n_{1}-\theta s_{1}\right)\left(n_{2}-\theta s_{2}\right)+c \theta^{2}\left[\left(n_{1}-\theta s_{1}\right) s_{2}^{2}+\left(n_{2}-\theta s_{2}\right) s_{1}^{2}\right]\right]} .
$$

In equilibrium, real wages are similar to nominal wage demands except that the inflationary response by the central bank, moderating changes in real wages by a factor (1- $\theta$ ). Taking partial derivatives shows that the real wage in country 1 is

- increasing in $n_{1}$ : a less centralized labor market in country 1 leads to higher wage demands because wage setters become more oblivious to the inflationary consequences of their action for the economy as a whole.

- decreasing in $n_{2}$ : the implied increase in foreign wages triggers an inflationary response from the central bank. Since labor unions in country 1 are inflation averse, the increase in inflation will only partly be compensated through higher nominal wage demands.

- decreasing in $c$ : making unions in countries 1 and 2 more inflation-averse will lead to lower nominal wages. Monetary policy will only partly accommodate this move by lowering inflation, resulting in higher real wages. 


\section{Voting Power, Inflation, and the Real Sector}

Assume, without loss of generality, an economically symmetric currency union with $\gamma=\chi=s_{1,2}=1 / 2$. In this setting, the representation of countries 1 and 2 in the common central bank based on the "one country, one vote" principle would be "ideal" in the sense that their political weight would exactly match their respective economic weight. With a symmetric distribution of economic size and voting power the central bank will set inflation to: ${ }^{5}$

$$
\pi_{\mid s_{1}=s_{2}}=\theta \cdot \frac{a\left(n_{2}-\theta / 2\right)\left(n_{2}-\theta / 2\right)}{a\left[a(1-\theta)\left(n_{1}-\theta / 2\right)\left(n_{2}-\theta / 2\right)+c(\theta / 2)^{2}\left[\left(n_{1}-\theta / 2\right)+\left(n_{2}-\theta / 2\right)\right]\right]} .
$$

How would a more asymmetric distribution of voting power - more akin to what we observe in reality - influence inflation and the real sector? It turns out that the answer is far from straightforward (see Appendix 1). But a helpful thought experiment can shed light on the issue: consider the case of extreme asymmetry between the two countries; that is, assume that $s_{1}$ goes to unity while $s_{2}$ approaches zero. ${ }^{6}$ In this scenario, the condition for asymmetric voting rights to reduce inflation compared to symmetric voting rights, i.e., $\pi_{\mid s_{1} \neq s_{2}}<\pi_{\mid s_{1}=s_{2}}$, is

$$
n_{1}\left(3-\frac{n_{1}}{n_{2}}\right)<\theta
$$

For $\theta>0$, a sufficient condition for (11) to be fulfilled is $n_{1} / n_{2}>3$, that is, the number of unions in country 1 should exceed the number of unions in country 2 by a significant degree.

We conclude that an increase in one country's political weight beyond its economic weight could decrease inflation if: (i) that country's labor market is significantly less centralized than that of the other country and (ii) the central bank's reaction to wage increases is strong. In such a scenario, the central bank council will aim to increase inflation to lower unemployment within the currency union. While the change of voting weights does not directly affect the real sector,

\footnotetext{
${ }^{5}$ Note that inflation aversion causes the externality between unions (Grüner and Hefeker 1999). Otherwise, unions fully internalize the effect of the changed environment, leading to similar inflation under both regimes.

${ }^{6}$ For instance, we could assume that $b=0$ (i.e., a zero bargaining weight for the ECB board) while $\gamma \rightarrow$ 1 (i.e., the relative weight of country 1's representative in the council approaches unity).
} 
weighted (or "perceived") unemployment will increase from the point of view of the central bank, because unemployment in country 1 exceeds unemployment in country 2 . This triggers a more expansionary monetary policy. As a consequence, unions in country 1 are facing higher rates of inflation at given real wages, leading to a moderation of wage demands under inflation aversion. This moderation effect is increasing in the strength of the central bank's initial reaction to the change in political weights, which, in turn, is a positive function of the difference in labor market centralization and the central bank's preference for high employment. As the result above shows, for a sufficiently strong reaction of the central bank, the moderation effect will be large enough to compensate the central bank's reaction. At the same time, unions in country 2 will increase wage demands-but only to some degree. While there is an incentive to increase wages as the central bank pays less attention to labor market developments in country 2 , unions are more sensitive to higher inflation from the increased weight of country 1 . The latter effect moderates wage demands in country 2 . As a consequence, overall currency union inflation could be falling. Vice versa, increasing the voting weight of a country with highly centralized labor markets could lead to an increase in inflation.

Is there a similar result for unemployment? Following the same approach, we find that the condition for unemployment in country 1 to decrease when we compare the asymmetric voting scenario with the symmetric scenario i.e., $u_{\mid s_{1} \neq s_{2}}<u_{\mid s_{1}=s_{2}}:^{7}$

$$
\frac{n_{1}-n_{2}}{n_{1}}>\frac{a 2(1-\theta)\left(n_{2}-\theta / 2\right)}{c \theta}
$$

Observe that the right-hand-side of the expression is increasing in $a$ but decreasing in $c$ and q. Regarding the labor market structure, also note that a necessary condition for (12a) to be fulfilled is $n_{1}>n_{2}$, that is, that country 1's labor market is less centralized than country 2's.

We conclude that an increase in country l's political weight beyond its economic weight could decrease unemployment in country 1 if: (i) country 1 's labor market is less centralized compared to country 2 's; (ii) unions are less averse to unemployment than to inflation; and (iii) the central bank's reaction to wage increases is strong. Vice versa, increasing the voting weight of a country with highly centralized labor markets, so that $n_{1}<n_{2}$, could lead to an increase in

\footnotetext{
${ }^{7}$ See Appendix 2 for the general condition.
} 
unemployment in that country.

Taking into account the above result on inflation, it would seem that there is a plausible scenario in which country 1 will be strictly better off after a central bank reform strengthening its political representation in the council. Note that this result does not require differences in business cycles or preferences but is driven solely by union behavior and labor market asymmetries.

How does country 2 fare with the decrease in its voting power in the council? Assuming that $s_{2}$ approaches zero, we find that $u_{2 \mid s_{1} \neq s_{2}}$ always exceeds $u_{2} \mid s_{1}=s_{2}$ because condition (12b)-which is related to (12a) but shows the condition for unemployment to increase-is always fulfilled:

$$
a(1-\theta)\left(n_{1}-\theta / 2\right)\left(n_{2}-\theta\right)+c\left(2 n_{1}-\theta\right) \theta^{2} / 2>0
$$

To summarize, a decrease in country 2 's political weight below its economic weight is likely to increase unemployment in country 2. The intuition behind this result is simply that, from the unions' perspective, reducing country 2's weight in the council to zero renders inflation exogenous, underniming the incentive to moderate wage demands to keep inflation low. ${ }^{8}$

As a consequence, the government in country 2 faces a trade off between unemployment and inflation: while a reduction in voting rights tends to bring down inflation, it is also likely to hurt employment. Nevertheless, if decision makers in country 2 are sufficiently conservative in the sense that they prefer the post-reform inflation/unemployment outcome to the pre-reform outcome (for instance, because of high levels of inflation), they are likely to support a decrease of their voting power in the council below the country's economic weight.

\section{Some Preliminary Evidence and Discussion}

An implication of the theoretical considerations above is that there could be a link between labor market structure and voting power in the ECB council. Recall that an increase in voting power in excess of a country's economic weight should hold greater attraction for countries with less centralized labor markets that hope to reduce unemployment. In other words, if the observed distribution of voting

\footnotetext{
${ }^{8}$ Of course, unions will discipline their wage demands to keep unemployment low, but the additional incentive to lower wage demands to restrain inflation low is lost. Thus, the three-dimensional trade-off between wages, unemployment, and inflation is changed, allowing higher wage demands.
} 
weights in the ECB council were influenced by similar arguments, we should expect a negative correlation between unemployment and voting power in excess of a country's economic weight. Along the same line, excess voting power should be negatively correlated with measures of centralization. Table 1 provides somealbeit very crude-measures for the latter, as well as indicators of excess voting power within the council and unemployment figures for current EMU members.

The indicators collected in Table 1 suggest that there is indeed some evidence of a negative relationship between excess voting power and unemployment. On average, countries which are currently politically overrepresented in the ECB council compared to their economic weight show lower unemployment rates than countries that are underrepresented (see lower panel). Moreover, while the small number of observations and the lack of other controls demand caution in interpreting such results, the conjectured negative relationship is also present in the negative coefficient of correlation of about -0.4 . The findings regarding centralization are less supportive. On average, overrepresented and underrepresented countries

Table 1. EMU 12: Excess Voting Power, Unemployment, and Labor Market Structure.

\begin{tabular}{lccccc}
\hline \multicolumn{1}{c}{ Country } & $\begin{array}{c}\text { Political Weight } \\
\text { (in percent) }\end{array}$ & $\begin{array}{c}\text { Economic } \\
\text { Weight } \\
\text { (in percent) }\end{array}$ & Difference & $\begin{array}{c}\text { Centralization } \\
\text { Index }\end{array}$ & $\begin{array}{c}\text { Unemployment } \\
\text { (2002, } \\
\text { in percent) }\end{array}$ \\
\hline Germany & 5.6 & 30.3 & -24.8 & 2.0 & 8.6 \\
France & 5.6 & 21.4 & -15.9 & 2.0 & 8.7 \\
Italy & 5.6 & 17.9 & -12.3 & 2.0 & 9.0 \\
Spain & 5.6 & 9.5 & -4.0 & 2.0 & 11.3 \\
Netherlands & 5.6 & 6.2 & -0.7 & 3.0 & 2.7 \\
Belgium & 5.6 & 3.8 & 1.8 & 2.0 & 7.3 \\
Austria & 5.6 & 3.1 & 2.5 & 3.0 & 4.3 \\
Finland & 5.6 & 2.0 & 3.6 & 2.0 & 9.1 \\
Greece & 5.6 & 1.9 & 3.6 & n.a. & 10.0 \\
Portugal & 5.6 & 1.8 & 3.8 & 3.0 & 5.1 \\
Ireland & 5.6 & 1.7 & 3.9 & 1.0 & 4.4 \\
Luxembourg & 5.6 & 0.3 & 5.2 & n.a. & 2.8 \\
\hline Average of countries underrepresented (,Difference “ $<0):$ & 2.2 & 8.1 \\
Average of countries overrepresented (,Difference“ $>0):$ & 2.2 & 6.1 \\
Correlation between the respective column and, Difference: & 0.18 & -0.43 \\
\hline
\end{tabular}

Sources: OECD; IFS; Riboud et al. (2002); Berger (2002); and own calculations.

Notes: "Political weight" takes into account votes allocated to the EXB board, "economic weight" is based on GDP, and the "difference" subtracts the latter from the former, making it a measure of excess voting power. The "centralization index" measures the degree of wage bargaining centralization (with higher figures indicating higher degrees of centralization). 
show similar degrees of centralization, and there is no trace of a negative relationship (the coefficient of correlation is small but positive) between centralization and excess voting power in the council. ${ }^{9}$ Nevertheless, we tentatively conclude that the data does not allow rejection of the idea that the current distribution of voting rights in the ECB council could, among other influences, reflect labor market characteristics as suggested in Section 4.

Are there policy implications regarding EMU enlargement? It is interesting to note that labor market centralization in relevant accession countries seems to fall short of the current EMU average. Riboud et al. (2002) report that the mean centralization index for Poland, The Czech Republic, Hungary, Slovenia, The Slovak Republic, and Estonia is about 1.8 compared to the 2.2 measured for today's EMU members (Table 1). Based on the theoretical arguments developed in section 4, one might conclude that these countries will (and perhaps should) be inclined to enter the currency union with voting rights exceeding their economic size. At the same time, it is far from clear whether current members would benefit from seeing their voting rights being reduced to accommodate such a suggestion.

As argued earlier, the willingness to accept voting rights short of relative economic size will, among other things, reflect present member's view of the unemployment/inflation tradeoff. With inflation around 2 percent or below, many current EMU members might find themselves unwilling to trade in even lower inflation for higher unemployment. This could help to explain why a majority of current members supports ECB reform that would protect the voting rights of current members. In addition, the potentially conflicting interest between current and future EMU members complicates policy conclusions. While one is tempted to speculate that the present asymmetrical vote distribution within the ECB council might have been in the best interest of all involved, a further increase in the overrepresentation of smaller member countries with enlargement might not.

\section{Concluding Remarks}

The likely enlargement of EMU has put the distribution of voting rights in the

\footnotetext{
${ }^{9}$ Labor market characteristics are notoriously hard to measure, and the low variance of the OECD's centralization indicator might be one of the reasons for this result. We also experimented with other indicators. There is, for instance, a positive correlation of about 0.5 between union coverage and the "difference" indicator in Table 1. To the extent that union coverage is a positive function of the number of unions active in a country (and, thus, perhaps indicative of less centralized wage negotiations), this finding seems to support the model.
} 
ECB council into the spotlight. In contrast to, for instance, the U.S. Federal Reserve or the pre-1999 German Bundesbank, voting rights in the ECB council are distributed according to the "one country, one vote" principle and independent of economic size. This potentially leaves smaller countries, including most potential EMU newcomers, a majority in the council. It has been argued that this might bias ECB decision making (by putting too large a weight on economic developments in these smaller countries) if national central bank governors hold national interests dearer to their hearts than the euro area aggregate.

So was the present ECB framework wrong in enforcing the "one country, one vote" principle at the neglect of economic size? There are reasons not to jump to conclusions. Adding to arguments resting on central bank independence or diversity in monetary transmission, we have argued that differences in labor market structure could play a role in explaining the existing vote distribution. In a model where monetary policy has real effects because labor unions internalize the inflationary consequences of wage setting, deviating from a pure seize-based voting scheme has different consequences for unemployment depending on the structure of national labor markets. Those overrepresented could benefit in terms of lower unemployment, especially if characterized by relatively decentralized or competitive labor markets. On the other hand, larger member countries, which are underrepresented within the present ECB voting framework, are likely to be confronted with less positive labor market outcomes. Nevertheless, such an arrangement could be in their interest to the extent that they take a conservative view on the inflation-unemployment trade-off. The reason is that inflation is likely to decline compared to a situation where voting rights are tailored to match economic weights. Preliminary evidence does not allow falsifying the notion that such considerations could be reflected in the present distribution of voting rights within the ECB council.

One implication of these results is that simply readjusting voting rights to decrease asymmetries by reducing the underrepresentation of EMU's larger member countries could entail costs. In particular, a large county with a highly centralized labor market structure might be facing both higher unemployment and inflation as its voting weight increases. This calls for some caution in reducing the current allocation of voting rights.

Does this imply that current plans for ECB reform are ill advised? This might be a question of perspective and the labor markdt characteristics of the countries involved. Without reform, the planned addition of up to ten mostly small countries 
to the euro area is bound to further increase existing asymmetries between voting rights and economic size. However, many of these future members are characterized by relatively decentralized labor markets which-according to the model-should help them profit from overrepresentation. On the other hand, for existing (often larger) members a further reduction in representation might not be as beneficial. This is because, with inflation already low by historical standards, the benefit of added wage discipline and inflation is less likely to compensate a potential increase in unemployment. Thus any policy conclusion regarding ECB reform prior to EMU enlargement will have to trade off welfare gains and losses in different member states.

\section{Acknowledgments}

We would like to thank Michael Funke, Nils Gottfries, and other participants of the CESifo Area Conference on Macro, Money, and International Finance in Munich, February 2004, for helpful comments.

Received 7 September 2004, Accepted 29 December 2004

\section{References}

Benigno, P. (2003) Optimal Monetary Policy in a Currency Area, Journal of International Economics (forthcoming).

Berger, H., J. de Haan, and S. Eijffinger (2001), Central Bank Independence: Update on Theory and Evidence, Journal of Economic Surveys, 15(1), 3-40.

Berger, H. (2002) The ECB and Euro-Area Enlargement, IMF Working Paper 02/175.

Berger, H. and J. de Haan (2002), Are Small Countries too Powerful Within the ECB?, Atlantic Economic Journal, 30(3), 2002, 1-20.

Calmfors, L. and J. Driffill (1988) Bargaining Structure, Corporatism and Macroeconomic Performance, Economic Policy 6, 13-62.

Casella, A. (1992) Participation in a Currency Union, American Economic Review 82, 847-864.

Cukierman, A. and F. Lippi (1999) Central Bank Independence, Centralization of Wage Bargaining, Inflation and Unemployment - Theory and Some Evidence, European Economic Review, 43, 1395-1434.

Cukierman, A. and F. Lippi (2001) Labor Markets and Monetary Union: A Strategic Analysis, Economic Journal 111, 541 -565.

Cubitt, R.P. (1992) Monetary Policy Games and Private Sector Precommitment, Oxford 
Economic Papers, 44, 513-530.

De Grauwe, P. (2000) Monetary Policies in the Presence of Asymmetries, Journal of Common Market Studies 38, 593-612.

Gros, D. and C. Hefeker (2002) One Size Must Fit All. National Divergences in a Monetary Union, German Economic Review 3, 247-262.

Grüner, H. P. (1999) On the Role of Conflicting National Interests in the ECB Council, CEPR Discussion Paper 2192.

Grüner, H. P. and C. Hefeker (1999) How Will EMU Affect Inflation and Unemployment in Europe?, Scandinavian Journal of Economics, 101(1), 33-47.

Guzzo, V. and A. Velasco (1999) The Case for a Populist Central Banker, European Economic Review, 43, 1317-1344.

Hefeker, C. (2003) Federal Monetary Policy, Scandinavian Journal of Economics 105, 641-659.

Lindbeck, A. and D. Snower (1988) The Insider-Outsider Theory of Employment and Unemployment, Cambridge: MIT-Press.

Meade, E. and N. Sheets (2002) Regional Influences on U.S. Monetary Policy: Some Implications for Europe, Board of Governors of the Federal Reserve System, International Finance Discussion Paper 721.

Riboud, M., C. Sanchez-Paramo and C. Silva-Jauregui (2002) Does Eurosclerosis Matter? Institutional Reform and Labor Market Performance in Central and Eastern European Countries in the 1990s, World Bank Social Protection Discussion Paper Series 0202.

Skott, P. (1997) Stagflationary Consequences of Prudent Monetary Policy in a Unionized Economy, Oxford Economic Papers 49, 609-622.

von Hagen, J. and R. Süppel (1994) Central Bank Constitutions for Federal Monetary Unions, European Economic Review 38, 774-782. 


\section{Appendix 1: Comparison of inflation rates}

Comparing equations (8) and (10) yields:

$$
\begin{gathered}
c\left(\theta^{\prime} 2\right)^{2} a\left(n_{1}+n_{2}-\theta\right)\left[a\left(n_{1}-\theta s_{1}\right)\left(n_{2}-\theta s_{2}\right)\right] \\
+c \theta^{2} s_{1} s_{2}\left(s_{1}-s_{2}\right)\left(n_{1} s_{2}-n_{2} s_{1}\right)\left[c(\theta / 2)^{2} a\left(n_{1}+n_{2}-\theta\right)+a^{2}(1-\theta)\left(n_{1}-\theta / 2\right)\left(n_{2}-\theta / 2\right)\right] \\
-c \theta^{2} a^{2}\left(n_{1}-\theta^{\prime} 2\right)\left(n_{2}-\theta^{\prime} 2\right)\left[s_{2}^{2}\left(n_{1}-\theta s_{1}\right)+s_{1}^{2}\left(n_{2}-\theta s_{2}\right)\right]
\end{gathered}
$$

The condition is not obviously fulfilled or not fulfilled. Setting $s_{1}=1$ gives expression (11).

\section{Appendix 2: Comparison of unemployment}

The condition for unemployment in country 1 to be lower with asymmetric voting rights is:

$$
\begin{gathered}
-a(1-\theta)\left(n_{2}-\theta / 2\right)\left(n_{2}-\theta s_{2}\right) n_{1}\left(s_{1}-1 / 2\right) \\
-c(\theta / 2)^{2}\left(s_{1}-s_{2}\right)\left[n_{2}\left(s_{2} n_{1}-s_{1} n_{2}\right)+n_{1}\left(n_{2}-\theta s_{2}\right)\right]<0 .
\end{gathered}
$$

Note that the sign of the first term depends on whether $s_{1}$ is smaller or larger than $1 / 2$. For the second term, the sign depends on the differences $s_{2} n_{1}-s_{1} n_{2}$ and which country holds more political power. For instance, a sufficient condition for condition (A2) to be fulfilled is $s_{1}>1 / 2>s_{2}$ and $n_{1}>n_{2}\left(s_{1} / s_{2}\right)$. Setting $s_{1}=1$ yields expression (12a). 